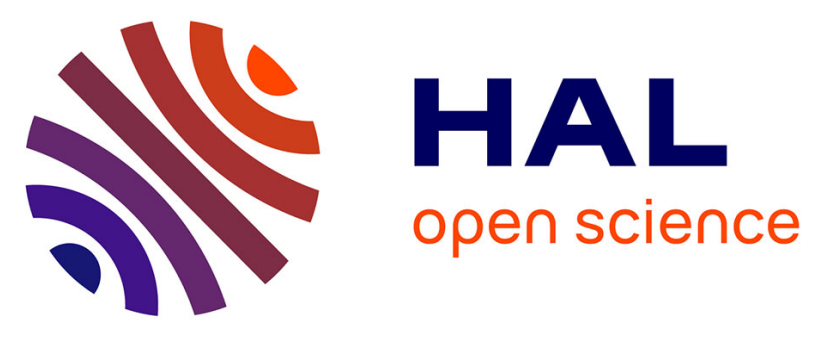

\title{
Thymoquinone protects rat liver after partial hepatectomy under ischemia/reperfusion through oxidative stress and endoplasmic reticulum stress prevention
}

\author{
Ahlem Bouhlel, Mohamed Bejaoui, Ismail Ben Mosbah, Najet Hadj Abdallah, \\ Catherine Ribault, Roselyne Viel, Hassen Hentati, Anne Corlu, Hassen Ben
} Abdennebi

\section{- To cite this version:}

Ahlem Bouhlel, Mohamed Bejaoui, Ismail Ben Mosbah, Najet Hadj Abdallah, Catherine Ribault, et al.. Thymoquinone protects rat liver after partial hepatectomy under ischemia/reperfusion through oxidative stress and endoplasmic reticulum stress prevention. Clinical and Experimental Pharmacology and Physiology, 2018, 45 (9), pp.943-951. 10.1111/1440-1681.12961 . hal-01808098

\section{HAL Id: hal-01808098}

https://hal-univ-rennes1.archives-ouvertes.fr/hal-01808098

Submitted on 4 Jul 2018

HAL is a multi-disciplinary open access archive for the deposit and dissemination of scientific research documents, whether they are published or not. The documents may come from teaching and research institutions in France or abroad, or from public or private research centers.
L'archive ouverte pluridisciplinaire HAL, est destinée au dépôt et à la diffusion de documents scientifiques de niveau recherche, publiés ou non, émanant des établissements d'enseignement et de recherche français ou étrangers, des laboratoires publics ou privés. 
Article type : Original Article

\section{Thymoquinone protects rat liver after partial hepatectomy under ischemia/reperfusion through oxidative stress and endoplasmic reticulum stress prevention}

Bouhlel Ahlem $^{\mathrm{a}}$, Bejaoui Mohamed ${ }^{\mathrm{a}}$, Ben mc sbah Ismail ${ }^{\mathrm{b}, \mathrm{c}}$, Hadj Abdallah Najet ${ }^{\mathrm{a}}$, Ribault Catherine $^{\mathrm{d}}$, Viel Roselyne ${ }^{\mathrm{e}}$, Hentati Hassen ${ }^{\mathrm{b}}$, Corlu Anne ${ }^{\mathrm{d}}$ and Ben Abdennebi Hassen ${ }^{\mathrm{a}^{*}}$

${ }^{a}$ Unité de Biologie et Anthropologie moléculaire appliquées au développement et à la santé (UR12ES11), Faculté de Pharmacie, Université de Monastir, Monastir, Tunisia.

${ }^{\mathrm{b}}$ Institut Mondor Recherche Biomédicale (IMRB), Université Paris-Est, Créteil, France.

${ }^{\mathrm{c}}$ Biopredic International, Rennes, France.

d INSERM, INRA, Université Rennes, Institut NUMECAN (Nutrition Metabolisms and Cancer) UMR_S1241, UMR_A 1341, F-35000 Rennes, France.

${ }^{\mathrm{e}}$ Université de Rennes 1, US18, UMS 3480 Biosit, Biogenouest, Plateforme H2P2

Short title: Thymoquinone effects on partial hepatectomy

*Corresponding author: Ben Abdennebi Hassen, Department of Physiology, Faculty of Pharmacy, University of Monastir, Rue Avicenne, Monastir 5000, Tunisia.

Tel: +21673461000

Fax: +21673461830 


\begin{abstract}
Ischemia reperfusion (I/R) is associated with liver injury and impaired regeneration during partial hepatectomy $(\mathrm{PH})$. The aim of this study was to investigate the effect of thymoquinone (TQ), the active compound of essential oil obtained from Nigella sativa seeds, on rat liver after PH.

Male Wistar rats were equally divided into four groups $(n=6)$ receiving an oral administration of either vehicle solution (Sham and PH groups) or TQ at $30 \mathrm{mg} / \mathrm{kg}$ (TQ and TQ+PH groups) for ten consecutive days. Then, rats underwent PH (70 \%) with $60 \mathrm{~min}$ of ischemia followed by $24 \mathrm{~h}$ of reperfusion (PH and TQ+PH groups). Alanine aminotransferase (ALT) activity and histopathological damage were determined. Also, antioxidant parameters, liver regeneration index, hepatic adenosine triphosphate (ATP) content, endoplasmic reticulum (ER) stress and apoptosis were assessed. In response to $\mathrm{PH}$ under $\mathrm{I} / \mathrm{R}$, liver damage was significantly alleviated by TQ treatment as evidenced by the decrease in ALT activity $(\mathrm{P}<0.01)$ and histological findings $(\mathrm{P}<0.001)$. In parallel, TQ preconditioning increased hepatic antioxidant capacities. Moreover, TQ improved mitochondrial function (ATP, $\mathrm{P}<0.05$ ), attenuated ER stress parameters and repressed the expression of apoptotic effectors. Taken together, our results suggest that TQ preconditioning could be an effective strategy to reduce liver injury after $\mathrm{PH}$ under I/R. The protective effects were mediated by the increase of antioxidant capacities and the decrease of ER stress and apoptosis.
\end{abstract}

\title{
Keywords:
}

Ischemia reperfusion injury, hepatectomy, thymoquinone, oxidative stress, endoplasmic reticulum stress, apoptosis. 


\section{Introduction}

Partial hepatectomy $(\mathrm{PH})$ is considered as the operation of choice for the treatment of many liver malignancies $(1,2)$ and for living donor liver transplantation (3). However, bleeding remains a major prognostic factor in liver resection. Complete clamping of the hepatic inflow at the hepatoduodenal ligament (the Pringle maneuver) is a safe strategy to alleviate this problem (4). This maneuver, although effective in preventing excessive blood loss, is complicated by ischemia/reperfusion (I/R) injury, which compromises functional recovery of the remnant liver $(4,5)$. Clinically, liver I/R injury results in elevated liver transaminases, bile duct stricture and even liver failure (4-6). Furthermore, other organs can develop dysfunction secondary to the liver damage such as lungs, heart and kidneys (7). Besides I/R, the surgical resection itself activates various complex cell signaling cascades of which many sides are still unresolved $(8,9)$. For example, reactive oxygen species (ROS) are involved in the modulation of several signaling pathways that may influence liver regeneration after $\mathrm{PH}(10,11)$. Also, mitochondria have been shown to be an important player of liver regeneration (12). Actually, high energy demand on the hepatocytes is required during the regenerative process after $\mathrm{PH}$ and this energy is provided by mitochondria through oxidative phosphorylation. In return, mitochondria release a large amount of $\operatorname{ROS}(13,14)$ which activate proteins that inhibit the cell cycle $(15,16)$. In addition, oxidative stress causes damage to cell components including proteins, lipids, and DNA resulting in cellular disorders and further organelle malfunction (17).

Endoplasmic reticulum (ER) stress is triggered in several pathological events such as hypoxia, glucose deprivation and oxidative stress. ER homeostasis disruption leads to the accumulation of unfolded and misfolded proteins in the ER lumen. As a consequence, unfolded protein response (UPR) is activated in order to resolve this protein-folding defect and so to restore ER homeostasis (18). However, if the UPR is insufficient to alleviate the stress, caspase 
dependent and independent cell death occurs (19). Indeed, ER stress activates caspase 12 and mitochondrial apoptosis pathway $(20,21)$. ER stress also upregulated glycogen synthase

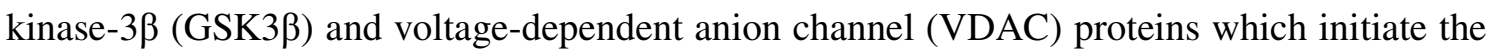
efflux of cytochrome $\mathrm{C}$ from the outer mitochondrial membrane, which in turn, activates the pro-apoptotic proteins caspase 9 and its effectors caspase 3 (22).

Thymoquinone (TQ) (2-isopropyl-5-methylbenzo-1, 4-quinone), is the major and the main active constituent of the essential oil of Nigella sativa seeds (23). TQ has several biological activities, especially antioxidant and free radical scavenging capacity $(24,25)$. Recently, it has been shown that TQ protects rat liver against I/R injury (20). However, its effect on liver subjected to resection under I/R is still unknown. Therefore, this study aimed to evaluate the effect of TQ administration in rat before a 2/3 hepatectomy (PH).

\section{Results}

In order to explore liver injury, we evaluated whether TQ pretreatment could preserve liver architecture and hepatocyte proliferation capacity after PH (Figure 1). As expected, a disorganized hepatic lobule aspect with focal necrosis was observed in rat livers subjected to PH under I/R. TQ treatment markedly attenuated the hepatic damage when compared to PH group $(2.3 \pm 0.3$ vs. $3.9 \pm 0.4, \mathrm{P}<0.001)$. We noted a relatively preserved hepatic architecture with less vacuolization and nuclear picnosis, and few zones of necrosis were detected. Consistent with these observations, we found that ALT activity in serum of PH+TQ group was significantly decreased when compared to $\mathrm{PH}$ group. Values reached $161 \pm 42$ and $74 \pm$ $46 \mathrm{U} / \mathrm{L}$ for $\mathrm{PH}$ and TQ+PH groups, respectively $(\mathrm{P}<0.01)$. We noted also that TQ treatment in sham operated rats (TQ group) did not result in any modification in ALT activity in comparison to sham group. In addition, hepatocyte proliferation, assessed 24 hours after PH by quantitation of the number of Ki-67-positive hepatocytes, was greater in TQ+PH group 
than in $\mathrm{PH}$ group $(7.7 \pm 5.8$ vs. $16.0 \pm 3.6 \%, \mathrm{P}<0.01)$. Thus, we could assume that the administration of TQ decreased hepatic damage and promoted liver regeneration.

It is well known that $\mathrm{PH}$ is associated with ROS production. We therefore examined the possible involvement of TQ in stimulating antioxidant systems. As shown in figure 2, PH under I/R resulted in a significant reduction in the antioxidant enzyme activities and increase in oxidative stress parameters. Interestingly, when compared to $\mathrm{PH}$ group, rats pre-treated with TQ had significantly increased activity of glutathione peroxidase (GPX) (271 \pm 43 vs. $209 \pm 21 \mu \mathrm{mol}$ oxided GSH$/ \mathrm{min} / \mathrm{mg}$ prot, $\mathrm{P}<0.05)$, superoxide dismutase (SOD) $(5.8 \pm 0.2$ vs. $5.0 \pm 0.4 \mathrm{U} / \mu \mathrm{g}$ prot, $\mathrm{P}<0.05)$ and catalase $(\mathrm{CAT})(140 \pm 18$ vs. $96 \pm 18 \mu \mathrm{mol}$ $\mathrm{H} 2 \mathrm{O} 2 / \mathrm{min} / \mathrm{mg}$ prot, $\mathrm{P}<0.01)$, sulfhydryl proteins (SHP) $(10 \pm 1$ vs. $6 \pm 3 \mu \mathrm{g} / \mathrm{mg}$ prot, $\mathrm{P}<$ $0.05)$ whereas they had reduced malondialdehyde (MDA) $(0.37 \pm 0.08$ vs. $0.70 \pm 0.15$ $\mathrm{nmol} / \mathrm{mg}$ prot, $\mathrm{P}<0.05)$ and conjugated dienes $(\mathrm{CD})(0.04 \pm 0.02$ vs. $0.07 \pm 0.0 .02 \mathrm{nmol} / \mathrm{mg}$ prot, $\mathrm{P}<0.05)$ concentrations. TQ treatment without $\mathrm{PH}$ did not result in any modification of oxidative stress parameters.

Given the central role for mitochondria to supply energy in cell, we assessed ATP concentration in livers (Figure 3). Our data showed that livers following ischemia and PH had a significant decrease in ATP content compared to livers from sham rats $(0.09 \pm 0.02$ vs. 0.71 $\pm 0.10 \mu \mathrm{mol} / \mathrm{mg}$ prot, $\mathrm{P}<0.001)$. However, pre-treatment with TQ enabled to preserve ATP content in comparison to $\mathrm{PH}$ group $(0.19 \pm 0.07 \mu \mathrm{mol} / \mathrm{mg}$ prot, $\mathrm{P}<0.05)$.

In order to evaluate whether the hepatoprotective effect of TQ could be related to ER stress prevention, protein relative expression of activating transcription factor-4 (ATF4), activating transcription factor-6 (ATF6) and X-box-binding protein-1 (XBP1) and protein concentration of glucose regulated protein 78 (GRP78) and C/EBP homologous protein (CHOP) were assessed (Figure 4). As expected, ischemia and PH markedly intensified the activation of all 
ER stress proteins when compared to sham group. As regarded to PH group, TQ pretreatment induced a significant drop in the expression of ATF4 $(\mathrm{P}<0.01)$, ATF6 $(\mathrm{P}<0.01)$ and XBP1 $(\mathrm{P}<0.01)$ proteins and in the concentration of GRP $78(519 \pm 229$ vs. $1143 \pm 350 \mu \mathrm{g} / \mathrm{mL}, \mathrm{P}<$ $0.001)$ and CHOP $(280 \pm 113$ vs. $490 \pm 60 \mu \mathrm{g} / \mathrm{mL}, \mathrm{P}<0.001)$.

Given that ER stress and mitochondrial dysfunction promote cell apoptosis $(20,26,27)$, we explored apoptosis proteins after PH under I/R (Figure 5). In concordance with the previous results, ischemia and $\mathrm{PH}$ increased apoptosis when compared to sham operated rats. Importantly, the apoptosis effectors were down-regulated by pretreatment with TQ. We found $289 \pm 80$ vs. $832 \pm 327 \mathrm{ng} / \mathrm{mL}(\mathrm{P}<0.001), 4.23 \pm 1.29$ vs. $9.57 \pm 1.58(\mathrm{P}<0.001), 4.76 \pm$ 0.84 vs. $9.54 \pm 1.98(\mathrm{P}<0.001)$ and $7.36 \pm 1.12$ vs. $16.37 \pm 2.35 \mathrm{pg} / \mathrm{mg}$ prot $(\mathrm{P}<0.001)$ for cytochrome c, caspase-9, caspase-12 and caspase-3 activities, respectively.

\section{Discussion}

This study demonstrates for the first time that TQ protects rat liver from injury caused by hepatectomy under $\mathrm{I} / \mathrm{R}$ and promoted hepatic regeneration through the induction of antioxidant defense capacity, the prevention of oxidative stress and the attenuation of ER stress, mitochondrial damage and apoptosis.

It was previously reported that TQ has many pharmacological actions, including antioxidant and anti-inflammatory effects against several hepatotoxic molecules (28-31). Moreover, it has been shown that TQ suppresses liver fibrosis $(32,33)$ and attenuates liver injury induced by ischemia $(20,34)$. Nevertheless, TQ effects have not been examined in an experimental model combining $\mathrm{PH}$ and $\mathrm{I} / \mathrm{R}$.

Partial hepatectomy under IR increased liver injury as evidenced by ALT release in serum. Besides, histopathological evaluation of the livers has confirmed liver damage. In contrast, rats pretreated with TQ before PH showed a reduction in liver injury and an improvement of 
the histopathological abnormalities. These findings consolidate previous reported works showing that TQ protects rat liver against IR injury $(20,34)$. In line with the decrease of liver injury, we found that TQ promoted liver regeneration. This is consistent with previous reports showing that TQ had healing effects in bone (35) and wound.

Thus far, the hepatoprotective effect of TQ is largely ascribed to its antioxidative properties. Imbalance between oxidants and antioxidants is commonly termed as oxidative stress. In response to this state, cells react by their antioxidant defense machinery including both nonenzymatic and enzymatic antioxidants (36). In our study, we found that PH under IR led to a decreased of SOD, GPx and CAT activities, of SHP concentration while it was accompanied by an increased MDA and CD contents. These results are in line with those of previous studies suggesting that free radical damage occurs in the early phase of liver regeneration (37) resulting in lipid peroxidation (38) and mitochondrial glutathione depression (39). Furthermore, we noticed that TQ attenuated PH injury by preserving the anti-oxidant enzyme activities and enhancing the level of SHP. As a result, lipid peroxidation evidenced by both MDA and CD concentrations were lessened. In fact, the antioxidant effect of TQ has been assigned to its ability to scavenge free radical $(40,41)$ and to up-regulate antioxidant gene expression $(42,43)$. Moreover, the action of TQ could be promoted by its unrestricted crossing of membrane barriers to access subcellular compartments and thus to protect them (25).

Further alterations touching cell organelles, including mitochondria, could be generated as a result of excessive ROS production. Previous data have hypothesized that oxidative stress induced by PH under IR impairs mitochondrial function and alters cell energy metabolism (37, 39). Moreover, hepatic regeneration could be affected by the change in mitochondrial energy production $(44,45)$. As previously reported, our study confirms the fact that $\mathrm{PH}$ under I/R decreases ATP production. In contrast, pre-treatment of rats with TQ led to the 
preservation of ATP stores in liver, which is in concordance with other works $(46,47)$. Thus, we can presume that the prevention of ATP drop would be due, at least in part, to the ability of TQ to preserve mitochondrial integrity.

The formation of ROS and the induction of ER stress are known to be closely linked processes (48). As a consequence of ER dysfunction, a signal transduction cascade which progress from the ER lumen to the cytoplasm and nucleus known as the UPR is activated (18). The UPR is an adaptive attempt that aims at restoring the ER homeostasis. It is mediated by three signaling proteins located at the ER membrane termed protein kinase RNA-like ER kinase (PERK), inositol requiring 1 (IRE1) and ATF6. The activation of these UPR sensors is impeded by their binding with a luminal protein chaperone, the glucose regulated protein 78 (GRP78). Once released from GRP78, the luminal domain of IRE1 dimerizes and transautophosphorylates and is thus transformed into an activated form. Activated IRE1 produces a potent transcription factor XBP1 by cleavage of XBP1 mRNA. The activated XBP1 upregulates UPR genes by directly binding to their related promoters (49). During ER stress, PERK is activated by a similar mechanism to IRE1. Activated PERK phosphorylates eukaryotic initiation factor 2 (eIF2 $\alpha$ ). Phosphorylated eIF2 $\alpha$ attenuates global protein synthesis by preventing ribosomal initiation complexes formation. Meanwhile, eIF $2 \alpha$ is necessary for translation of some mRNAs, including the mRNA that encodes the ATF4. ATF4 regulates several UPR target genes principally those engaged in antioxidative stress responses, autophagy and ER stress-induced apoptosis such as CHOP (50, 51). Upon GRP78 release, ATF6 translocates from the ER to the Golgi where it is cleaved to form an active transcription factor. Active ATF6 migrates then to the nucleus and up-regulates numerous ER chaperone genes including GRP78, GRP94, and CHOP (52). Our data revealed the activation of all three branches of UPR (PERK, ATF6, IRE1) and their downstream targets ATF4, ATF6 $\alpha$, XBP1, respectively. We also showed the presence of ER stress in PH under IR 
condition by the induction of CHOP and the up-regulation of GRP78. These results are in line with those of a previous report which highlighted ER stress after PH (21). In our study, we demonstrated that the induction of ER stress parameters in response to PH under IR condition could be reduced by TQ pre-treatment. Our data are in keeping with our previous findings showing that TQ reduces ER stress induced by warm liver IR in rat (20). However, how TQ protects ER from $\mathrm{PH}$ under I/R damage remains unclear; we presume that it could be related to the attenuation of oxidative stress.

Mitochondrial damage and ER stress induction by $\mathrm{PH}$ under I/R condition prompted us to further evaluate apoptosis. In the present study, an increase of cytochrome $\mathrm{C}$ release was observed after PH. In addition, both caspase-9 and -3 were found activated which indicates that PH under I/R may stimulate apoptotic cell death $(53,54)$. In parallel, our data showed a caspase-12 induction, which is known as an important protein implicated in ER-induced apoptosis (55). In our experimental model, TQ induced down-regulation of cytochrome C release and a marked decrease in the expression of caspase-9, -12 and -3 . These findings are in line with a previous research paper (34). The anti-apoptotic effect of TQ could be attributed to its potent scavenger and antioxidant role that help to attenuate ER stress and further apoptosis.

In summary, this study is the first to evaluate the hepatoprotective effects of TQ in an experimental model of PH. Data reported here suggest that TQ plays an important role in the prevention of liver injury in conditions of hepatectomy under I/R. TQ protection is related to its capacity to prevent oxidative stress, mitochondrial damage, ER stress and apoptosis. 


\section{Materials and methods}

\section{Experimental animals and Ethics Statement}

Male Wistar rats weighing 200-230 g were used in this study. They were housed in an aircontrolled room with $12 \mathrm{~h}$ light and dark cycles, and a constant temperature $\left(22 \pm 2^{\circ} \mathrm{C}\right)$. They had free access to food and water. All procedures were carried out in accordance with the European Union Regulations (Directive 2010/63/EU) for animal experiments and approved by the local Experimental Animals Ethics Committee of the Faculty of Pharmacy of Monastir.

\section{Surgical Procedure}

Rats were anaesthetized with an intra-peritoneal (ip) injection of pentobarbital (5\%), and then subjected to $\mathrm{PH}$ (70 \% of liver parenchyma) under $60 \mathrm{~min}$ of ischemia as described previously (21). Briefly, after dividing the ligaments of the hepatic lobes and resection of their left hepatic lobe, rats underwent 60 min of partial liver warm ischemia by clamping their portal triad supplying the median lobe. At the end of ischemia, the right and caudate lobes were resected, and reperfusion of the median lobe was achieved by the release of the clamp. Sham operated rats was subjected to anesthesia and pedicle dissection without resection or ischemia. After surgery, rats were allowed food and water ad libitum. Blood and liver samples were collected after $24 \mathrm{~h}$ reperfusion and samples were stored at $-80^{\circ} \mathrm{C}$.

\section{Experimental groups}

Rats were allocated at random into four experimental groups, with six rats in each group:

Group 1 (Sham group): Rats were subjected to only laparotomy without occlusion of hepatic pedicle and $\mathrm{PH}$.

Group 2 (TQ group): rats were orally pretreated with TQ (30 mg/kg) for ten consecutive days (20). Rat livers were then subjected to laparotomy without occlusion of hepatic pedicle and $\mathrm{PH}$. 
Group 3 (PH group): rats underwent $70 \%$ hepatectomy under 60 min of ischemia followed by $24 \mathrm{~h}$ of reperfusion.

Group 4 (TQ+PH group): rats were orally pretreated with TQ (30 mg/kg) for ten consecutive days (20). Rat livers were then subjected to surgery as in group 3.

\section{Chemicals}

TQ (Sigma Aldrich) was dissolved in ethanol and aliquoted and stored at $-20^{\circ} \mathrm{C}$. Working solution was prepared daily before oral administration by diluting stock solution with distilled water (1:4). Ten days prior the surgery, sham and $\mathrm{PH}$ animals underwent a daily intragastric administration of vehicle solution (ethanol and distilled water) as described previously (20).

\section{Histology and Immunohistochemistry}

Liver biopsies were fixed in $10 \%$ formalin solution, embedded in paraffin and cut at $4 \mu \mathrm{m}$ thickness. To appraise the severity of hepatic injury, stained sections with hematoxylin and eosin were graded with a point-counting method on a scale from 1 (excellent) to 5 (poor) as described previously (56): (1) normal rectangular structure, (2) rounded hepatocytes with an increase of the sinusoidal spaces, (3) vacuolization, (4) nuclear picnosis and (5) necrosis. Damage score was estimated semi-quantitatively by an experienced pathologist without having knowledge about the treatment groups.

For liver regeneration, liver samples were immunostained with a rabbit monoclonal antibody against Ki 67 (clone SP6, Abcam, Cambridge, MA), developed with diaminobenzidine, and counterstained with hematoxylin (57).

\section{Transaminase determination}

The serum activity of alanine aminotransferase (ALT) was determined using a commercial kit from DiaSys (Diagnostic System, Germany) following supplier's instructions.

\section{Determination of hepatic adenosine triphosphate content}


Hepatic adenosine triphosphate (ATP) measurements were performed using a firefly bioluminescence assay kit (ATP Bioluminescent Assay Kit FLAA-1KT, Sigma Aldrich St Quentin Fallavier, France) as described elsewhere (58).

\section{Determination of oxidative stress parameters}

Liver tissues were homogenized in ice-cold phosphate buffered saline $\left(100 \mathrm{mM} \mathrm{KH}_{2} \mathrm{PO}_{4}, 100\right.$ $\mathrm{mM} \mathrm{K} \mathrm{HPO}_{4}, \mathrm{pH}$ 7.4) to estimate the content of SHP and the activities of GPx, SOD and CAT. For MDA determination, tissues homogenization was carried out in ice-cold trisbuffered saline (100 mM Tris, pH 7). For CD measurement, liver tissues were homogenized in distilled ice-water.

Liver GPx activity was estimated by the method of Floche and Gunzler 1984 (59). SOD activity assay was performed using the method previously described by Marklund and Marklund (60). CAT activity was determined according to Clairbone method (61). The determination of SHP level was achieved in agreement to the method of Sedlak (62). MDA was measured by the thiobarbituric acid (TBA) assay (63). CD was assessed according to Srinivasan (64).

\section{Determination of endoplasmic reticulum stress parameters}

We looked for ER stress through the determination of GRP78 and CHOP using ELISA kits (MyBioSource, San Diego, CA) according to the manufacturer's protocol and by the determination of protein relative expression of ATF6 $\alpha$, ATF4 and XBP1 by western blot technique.

Briefly, liver tissues were homogenized in ice-cold lysis buffer (150 mM NaCl, $50 \mathrm{mM}$ Tris$\mathrm{HCl}(\mathrm{pH}$ 7.5), $1 \mathrm{mM}$ DTT, $50 \mathrm{mM}$ NaF, $1 \mathrm{mM}$ PMSF, 1 mM EDTA, $1 \mathrm{mM}$ EGTA, $0.1 \mathrm{mM}$

orthovanadate, $0.05 \%$ Triton-X 100 and $2 \%$ protease inhibitor cocktails). Equal amounts of proteins were separated by SDS-PAGE and transferred to PVDF membranes as described elsewhere (65). Then, membranes were incubated over night at $4^{\circ} \mathrm{C}$ with primary antibodies 
for ATF6 $\alpha$ (sc-22799), ATF4 (sc-101663), XBP1 (sc-7160) and Hsc70 (sc-7298) acquired from Santa Cruz Biotechnology. After washing, the membranes were incubated for $2 \mathrm{~h}$ at room temperature with appropriate horseradish peroxydase conjugated secondary antibody. Signals were detected by enhanced chemiluminescence and quantified by the quantity one software program (Bio-Rad Laboratories, Hercules, CA, USA).

\section{Determination of apoptosis parameters}

Cytochrome C level was evaluated using ELISA kit from MyBioSource (San Diego, CA). A fluorometric assay kit was used (Biovision Palo Alto, CA) to determine liver caspase 12 level. Caspase 9 and caspase 3 levels were measured using a colorimetric assay kit from Biovision (Palo Alto, CA).

\section{Statistical analysis}

Data were expressed as mean \pm standard deviation $(\mathrm{SD})$ and were compared statistically using Graph Pad Prism software (version 6.01) by variance of analysis (ANOVA) followed by Newman-Keuls multiple comparison test. P-value of less than 0.05 was considered statistically significant.

\section{Acknowledgements}

This work was supported by grant from the Tunisian Ministry of Higher Education and Scientific Research (UR12ES11).

The authors declare that they have no conflicts of interests concerning this article.

\section{REFERENCES}

1. Parkin DM, Bray F, Devesa S. Cancer burden in the year 2000. The global picture. European journal of cancer 2001; 37:4-66.

2. Kanematsu T, Takenaka K, Matsumata T, Furuta T, Sugimachi K, Inokuchi K. Limited hepatic resection effective for selected cirrhotic patients with primary liver cancer. Annals of surgery 1984; 199:51. 
3. Cherqui $D$, Soubrane $O$, Husson $E$, et al. Laparoscopic living donor hepatectomy for liver transplantation in children. The Lancet 2002; 359:392-6.

4. Kim YI. Ischemia-reperfusion injury of the human liver during hepatic resection. $J$ Hepatobiliary Pancreat Surg 2003; 10:195-9.

5. Serracino-Inglott F, Habib NA, Mathie RT. Hepatic ischemia-reperfusion injury. Am J Surg 2001; 181:160-6.

6. Theodoraki K, Karmaniolou I, Tympa A, et al. Beyond Preconditioning: Postconditioning as an Alternative Technique in the Prevention of Liver Ischemia-Reperfusion Injury. Oxid Med Cell Longev 2016; 2016:8235921.

7. Nastos C, Kalimeris K, Papoutsidakis N, et al. Global consequences of liver ischemia/reperfusion injury. Oxid Med Cell Longev 2014; 2014:906965.

8. Michalopoulos GK, DeFrances MC. Liver regeneration. Science 1997; 276:60-6.

9. $\quad$ Fausto N. Liver regeneration. Journal of hepatology 2000; 32:19-31.

10. Forman HJ, Torres M, Fukuto J. Redox signaling. In. Oxygen/Nitrogen Radicals: Cell Injury and Disease. Springer. 2002.

11. Finkel T, Holbrook NJ. Oxidants, oxidative stress and the biology of ageing. Nature 2000; 408:239-47.

12. Alexandrino $\mathrm{H}$, Varela AT, Teodoro JS, et al. Mitochondrial bioenergetics and posthepatectomy liver dysfunction. Eur J Clin Invest 2016; 46:627-35.

13. Guerrieri F, Muolo L, Cocco T, et al. Correlation between rat liver regeneration and mitochondrial energy metabolism. Biochimica et Biophysica Acta (BBA)-Molecular Basis of Disease 1995; 1272:95-100.

14. Mann DV, Lam WW, Hjelm NM, et al. Human liver regeneration: hepatic energy economy is less efficient when the organ is diseased. Hepatology 2001; 34:557-65.

15. Barnouin K, Dubuisson ML, Child ES, et al. H2O2 induces a transient multi-phase cell cycle arrest in mouse fibroblasts through modulating cyclin D and p21Cip1 expression. Journal of Biological Chemistry 2002; 277:13761-70.

16. Mendelson KG, Contois L-R, Tevosian SG, Davis RJ, Paulson KE. Independent regulation of $\mathrm{JNK} / \mathrm{p} 38$ mitogen-activated protein kinases by metabolic oxidative stress in the liver. Proceedings of the National Academy of Sciences 1996; 93:12908-13.

17. Moustafa AM, Boshra V. Effect of fenofibrate on the experimentally induced hepatic ischemia/reperfusion injury in rats: biochemical, light, and electron microscopic studies. Egyptian Journal of Histology 2011; 34:103-16.

18. Wang D, Wei Y, Pagliassotti MJ. Saturated fatty acids promote endoplasmic reticulum stress and liver injury in rats with hepatic steatosis. Endocrinology 2006; 147:943-51.

19. Ron D. Translational control in the endoplasmic reticulum stress response. The Journal of clinical investigation 2002; 110:1383-8.

20. Bouhlel A, Ben Mosbah I, Hadj Abdallah N, et al. Thymoquinone prevents endoplasmic reticulum stress and mitochondria-induced apoptosis in a rat model of partial hepatic warm ischemia reperfusion. Biomed Pharmacother 2017; 94:964-73.

21. Mosbah IB, Alfany-Fernández I, Martel C, et al. Endoplasmic reticulum stress inhibition protects steatotic and non-steatotic livers in partial hepatectomy under ischemia-reperfusion. Cell death \& disease 2010; 1:e52.

22. Panzarini E, Inguscio V, Dini L. Timing the multiple cell death pathways initiated by Rose Bengal acetate photodynamic therapy. Cell death \& disease 2011; 2:e169.

23. Saleh IA, Billedo G, Doush II. Levels of selenium, dl- $\alpha$-tocopherol, dl- $\psi$-tocopherol, alltransretinol, thymoquinone and thymol in different brands of Nigella sativa seeds. Journal of Food Composition and Analysis 2006; 19:167-75.

24. Mansour MA, Ginawi OT, El-Hadiyah T, El-Khatib AS, Al-Shabanah OA, Al-Sawaf HA. Effects of volatile oil constituents of Nigella sativa on carbon tetrachloride-induced hepatotoxicity in mice: evidence for antioxidant effects of thymoquinone. Research communications in molecular pathology and pharmacology 2001; 110:239-51. 
25. Osama A. Badary, Ragia A. Tahaa, El-Dinb AMG, Abdel-Wahaba MH. Thymoquinone Is a Potent Superoxide Anion Scavenger. Drug and Chemical Toxicology 2003; 26: 87-98.

26. Cao L, Quan XB, Zeng WJ, Yang XO, Wang MJ. Mechanism of Hepatocyte Apoptosis. J Cell Death 2016; 9:19-29.

27. Weng J, Li W, Jia X, An W. Alleviation of Ischemia-Reperfusion Injury in Liver Steatosis by Augmenter of Liver Regeneration Is Attributed to Antioxidation and Preservation of Mitochondria. Transplantation 2017; 101:2340-8.

28. Mansour MA. Protective effects of thymoquinone and desferrioxamine against hepatotoxicity of carbon tetrachloride in mice. Life sciences 2000; 66:2583-91.

29. Nagi MN, Alam K, Badary OA, Al-Shabanah OA, Al-Sawaf HA, Al-Bekairi AM. Thymoquinone protects against carbon tetrachloride hetatotoxicity in mice via an antioxidant mechanism. IUBMB Life 1999; 47:153-9.

30. Ragheb A, Attia A, Eldin WS, Elbarbry F, Gazarin S, Shoker A. The protective effect of thymoquinone, an anti-oxidant and anti-inflammatory agent, against renal injury: a review. Saudi journal of kidney diseases and transplantation : an official publication of the Saudi Center for Organ Transplantation, Saudi Arabia 2009; 20:741-52.

31. Woo CC, Kumar AP, Sethi G, Tan KH. Thymoquinone: potential cure for inflammatory disorders and cancer. Biochemical pharmacology 2012; 83:443-51.

32. Oguz $S$, Kanter $M$, Erboga $M$, Erenoglu C. Protective effects of thymoquinone against cholestatic oxidative stress and hepatic damage after biliary obstruction in rats. Journal of molecular histology 2012; 43:151-9.

33. Bai T, Lian LH, Wu YL, Wan Y, Nan JX. Thymoquinone attenuates liver fibrosis via PI3K and TLR4 signaling pathways in activated hepatic stellate cells. International immunopharmacology 2013; 15:275-81.

34. Abd El-Ghany RM, Sharaf NM, Kassem LA, Mahran LG, Heikal OA. Thymoquinone triggers anti-apoptotic signaling targeting death ligand and apoptotic regulators in a model of hepatic ischemia reperfusion injury. Drug discoveries \& therapeutics 2009; 3:296-306.

35. Kirui PK, Cameron J, Benghuzzi HA, et al. Effects of sustained delivery of thymoqiunone on bone healing of male rats. Biomed Sci Instrum 2004; 40:111-6.

36. Kleikers PW, Wingler K, Hermans J, et al. NADPH oxidases as a source of oxidative stress and molecular target in ischemia/reperfusion injury. Journal of molecular medicine 2012; 90:1391-406.

37. Steer CJ. Liver regeneration. The FASEB Journal 1995; 9:1396-400.

38. Aguilar-Delfin I, López-Barrera F, Hernández-Munoz R. Selective enhancement of lipid peroxidation in plasma membrane in two experimental models of liver regeneration: partial hepatectomy and acute CCl4 administration. Hepatology 1996; 24:657-62.

39. Vendemiale G, Guerrieri F, Grattagliano I, Didonna D, Muolo L, Altomare E. Mitochondrial oxidative phosphorylation and intracellular glutathione compartmentation during rat liver regeneration. Hepatology 1995; 21:1450-4.

40. Khalife K, Lupidi G. Nonenzymatic reduction of thymoquinone in physiological conditions. Free radical research 2007; 41:153-61.

41. Khattab MM, Nagi MN. Thymoquinone supplementation attenuates hypertension and renal damage in nitric oxide deficient hypertensive rats. Phytotherapy Research 2007; 21:410-4.

42. Ismail M, Al-Naqeep G, Chan KW. Nigella sativa thymoquinone-rich fraction greatly improves plasma antioxidant capacity and expression of antioxidant genes in hypercholesterolemic rats. Free Radical Biology and Medicine 2010; 48:664-72.

43. Sayed-Ahmed MM, Aleisa AM, Al-Rejaie SS, et al. Thymoquinone attenuates diethylnitrosamine induction of hepatic carcinogenesis through antioxidant signaling. Oxidative medicine and cellular longevity 2010; 3:254-61.

44. Horimoto M, Fülöp P, Derdák Z, Wands JR, Baffy G. Uncoupling protein-2 deficiency promotes oxidant stress and delays liver regeneration in mice. Hepatology 2004; 39:386-92.

45. Beyer TA, Werner S. The cytoprotective Nrf2 transcription factor controls insulin receptor signaling in the regenerating liver. Cell Cycle 2008; 7:874-8. 
46. Sayed-Ahmed MM, Nagi MN. THYMOQUINONE SUPPLEMENTATION PREVENTS THE DEVELOPMENT OF GENTAMICIN-INDUCED ACUTE RENAL TOXICITY IN RATS. Clinical and Experimental Pharmacology and Physiology 2007; 34:399-405.

47. Nagi MN, Al-Shabanah OA, Hafez MM, Sayed-Ahmed MM. Thymoquinone supplementation attenuates cyclophosphamide-induced cardiotoxicity in rats. Journal of biochemical and molecular toxicology 2011; 25:135-42.

48. Malhotra JD, Kaufman RJ. Endoplasmic reticulum stress and oxidative stress: a vicious cycle or a double-edged sword? Antioxid Redox Signal 2007; 9:2277-93.

49. Yeganeh B, Alizadeh J, Wiechec E, et al. Hepatitis B and C virus-induced hepatitis: Apoptosis, autophagy, and unfolded protein response. World journal of gastroenterology 2015; 21:13225-39.

50. Harding $\mathrm{HP}$, Zhang $\mathrm{Y}$, Zeng $\mathrm{H}$, et al. An integrated stress response regulates amino acid metabolism and resistance to oxidative stress. Molecular cell 2003; 11:619-33.

51. Harding HP, Novoa I, Zhang $\mathrm{Y}$, et al. Regulated translation initiation controls stress-induced gene expression in mammalian cells. Mol Cell 2000; 6:1099-108.

52. Zeeshan HMA, Lee GH, Kim H-R, Chae H-J. Endoplasmic reticulum stress and associated ROS. International journal of molecular sciences 2016; 17:327.

53. Szegezdi E, Fitzgerald U, Samali A. Caspase-12 and ER-stress-mediated apoptosis: the story so far. Annals of the New York Academy of Sciences 2003; 1010:186-94.

54. Badiola N, Penas C, Minano-Molina A, et al. Induction of ER stress in response to oxygenglucose deprivation of cortical cultures involves the activation of the PERK and IRE-1 pathways and of caspase-12. Cell death \& disease 2011; 2:e149.

55. Chung P-S, He P, Shin J-I, Hwang H-J, Lee SJ, Ahn J-C. Photodynamic therapy with 9hydroxypheophorbide $\alpha$ on AMC-HN-3 human head and neck cancer cells: induction of apoptosis via photoactivation of mitochondria and endoplasmic reticulum. Cancer biology \& therapy 2009; 8:134351.

56. Ben Mosbah I, Mouchel Y, Pajaud J, et al. Pretreatment with mangafodipir improves liver graft tolerance to ischemia/reperfusion injury in rat. PloS one 2012; 7:e50235.

57. Schiffer E, Frossard JL, Rubbia-Brandt L, Mentha G, Pastor CM. Hepatic regeneration is decreased in a rat model of sinusoidal obstruction syndrome. J Surg Oncol 2009; 99:439-46.

58. Bejaoui $M$, Pantazi $E$, De Luca $V$, et al. Acetazolamide protects steatotic liver grafts against cold ischemia reperfusion injury. J Pharmacol Exp Ther 2015; 355:191-8.

59. Flohé L, Günzler WA. [12] Assays of glutathione peroxidase. In. Methods in Enzymology. Academic Press. 1984.

60. Marklund S, Marklund G. Involvement of the Superoxide Anion Radical in the Autoxidation of Pyrogallol and a Convenient Assay for Superoxide Dismutase. European Journal of Biochemistry 1974; 47:469-74.

61. Claiborne A. Catalase activity. Handbook of methods for oxygen radical research 1985: 283-4.

62. Sedlak J, Lindsay RH. Estimation of total, protein-bound, and nonprotein sulfhydryl groups in tissue with Ellman's reagent. Analytical biochemistry 1968; 25:192-205.

63. Ben Mosbah I, Roselló-Catafau J, Franco-Gou R, et al. Preservation of steatotic livers in IGL-1 solution. Liver transplantation 2006; 12:1215-23.

64. Srinivasan $\mathrm{S}$, Xiong YL, Decker EA. Inhibition of protein and lipid oxidation in beef heart surimi-like material by antioxidants and combinations of $\mathrm{pH}, \mathrm{NaCl}$, and buffer type in the washing media. Journal of Agricultural and Food Chemistry 1996; 44:119-25.

65. Hadj Ayed Tka K, Mahfoudh Boussaid A, Zaouali MA, et al. Melatonin modulates endoplasmic reticulum stress and Akt/GSK3-beta signaling pathway in a rat model of renal warm ischemia reperfusion. Analytical cellular pathology (Amsterdam) 2015; 2015:635172. 


\section{Figure legends:}

Figure 1. Thymoquinone prevented liver injury and promoted regeneration after $\mathrm{PH}$.

(a) H\&E staining of the liver section in the Sham, $\mathrm{PH}$ and TQ+PH groups. Arrows pointed out the necrotic areas. Scale bar represents $100 \mu \mathrm{m}$, (b) damage score, (c) ALT activity in plasma, (d) immunostaining of Ki67 of the liver section in the PH and TQ+PH groups. Scale bar represents $300 \mu \mathrm{m}$ and (e) representative immunohistochemical analysis showing the percentage of Ki67 positive cells. Results are expressed as mean \pm SD ( $n=6$ for each group). $* \mathrm{P}<0.05$ versus Sham. $+\mathrm{P}<0.05$ versus TQ. $\# \mathrm{P}<0.05$ versus $\mathrm{PH}$.

Figure 2. Thymoquinone pretreatment attenuated oxidative stress after PH under I/R.

Liver samples were assessed for MDA concentration (a), glutathione peroxidase activity (b), superoxide dismutase activity (c), catalase activity (d), sulfhydryl proteins content (e) and conjugated dienes concentration (f) in livers harvested from Sham, TQ, PH and TQ+PH groups. Results are expressed as mean $\pm \mathrm{SD}$ ( $\mathrm{n}=6$ for each group). ${ }^{*} \mathrm{P}<0.05$ versus Sham. $+\mathrm{P}<0.05$ versus TQ. \#P<0.05 versus $\mathrm{PH}$.

Figure 3. Thymoquinone increased ATP content in liver after $\mathrm{PH}$.

ATP concentration in liver tissue of Sham, PH and TQ+PH groups. Results are expressed as mean $\pm \mathrm{SD}$ ( $\mathrm{n}=6$ for each group). ${ }^{*} \mathrm{P}<0.05$ versus Sham. $\# \mathrm{P}<0.05$ versus $\mathrm{PH}$.

Figure 4. Thymoquinone preconditioning attenuated ER stress.

GRP78 (a) and CHOP (b) concentration determined by ELISA kits and the relative expression of ATF6 (c), ATF4 (d) and XBP1 (e) proteins level evaluated by western blot in Sham, PH and TQ+PH groups. Results are expressed as mean $\pm \mathrm{SD}\left(\mathrm{n}=6\right.$ for each group). ${ }^{*} \mathrm{P}<0.05$ versus Sham. \#P<0.05 versus $\mathrm{PH}$.

Figure 5. Thymoquinone pretreatment decreased liver apoptosis after $\mathrm{PH}$.

Caspase 12 (a), Cytochrome C (b) Caspase 9 (c) and Caspase 3 (d) concentrations were determined. Livers were harvested from Sham, $\mathrm{PH}$ and TQ+PH groups. Results are expressed as mean $\pm \mathrm{SD}$ ( $\mathrm{n}=6$ for each group). ${ }^{*} \mathrm{P}<0.05$ versus Sham. $\# \mathrm{P}<0.05$ versus $\mathrm{PH}$. 
(a)

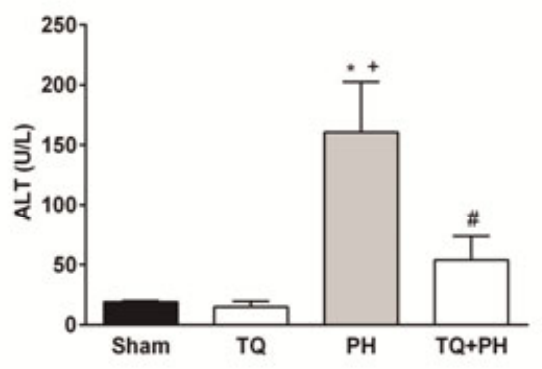

(c)

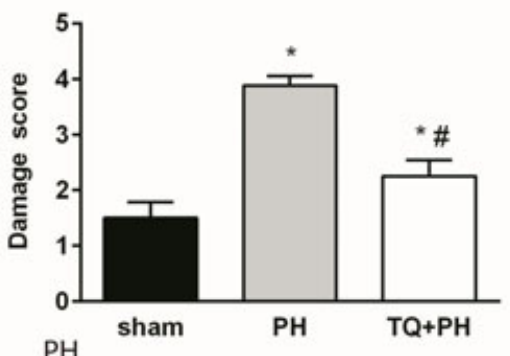

(b)

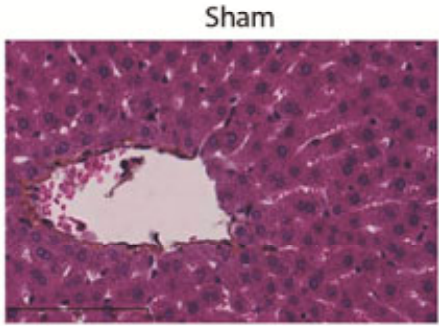

$\mathrm{PH}$
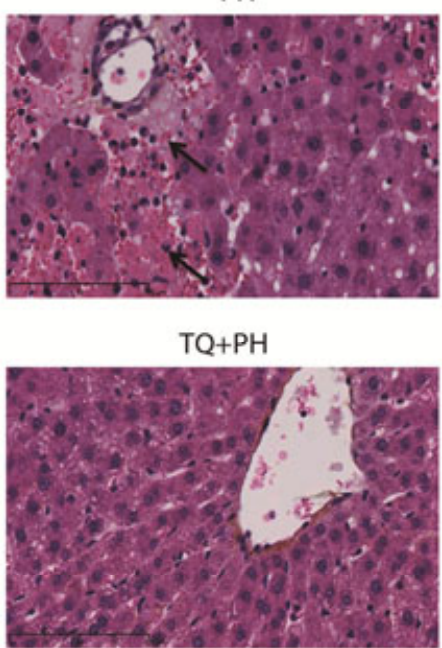

(e)

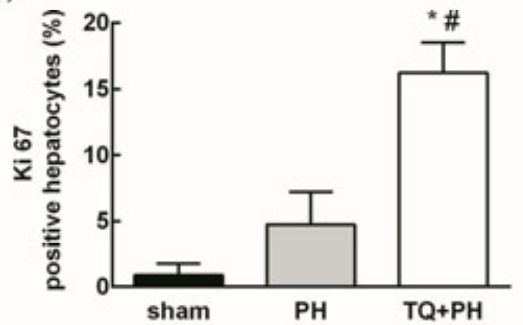

Figure 1 
(a)

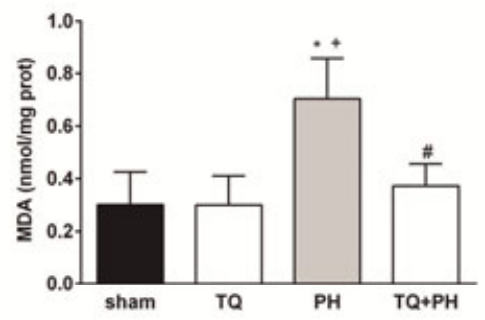

(c)

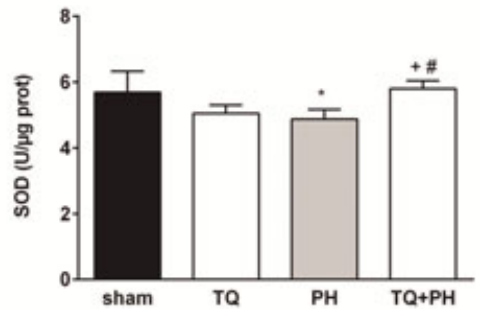

(e)

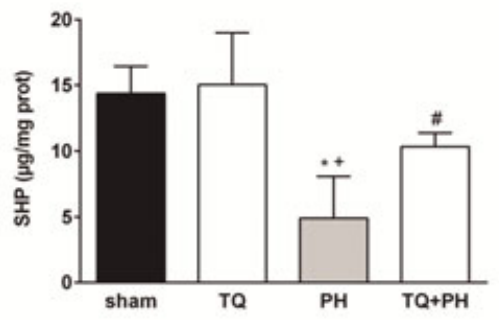

(b)

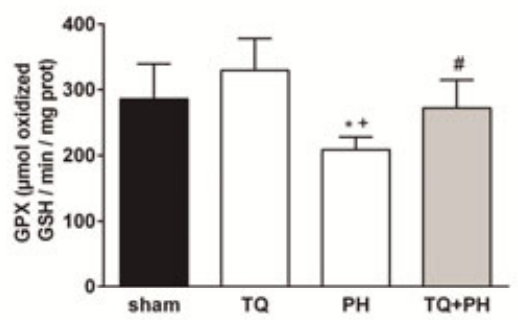

(d)

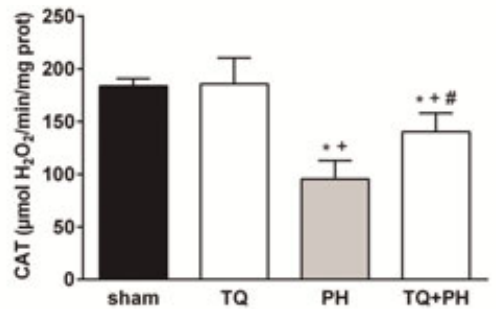

(f)

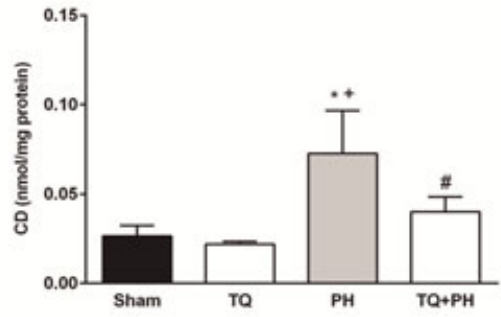

Figure 2 


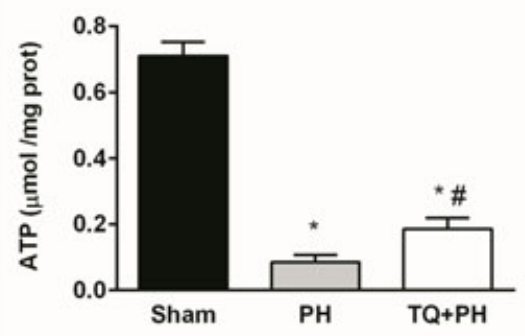

Figure 3 
(a)

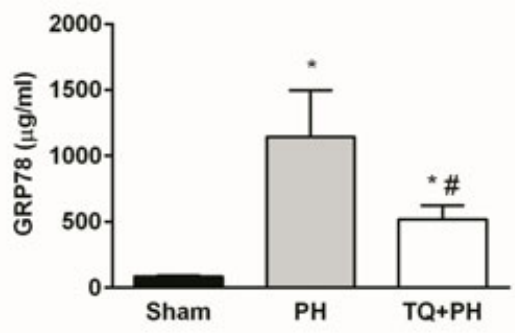

(c)
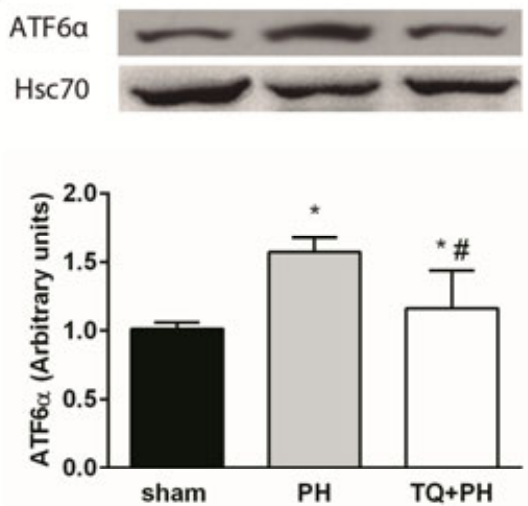

(e)
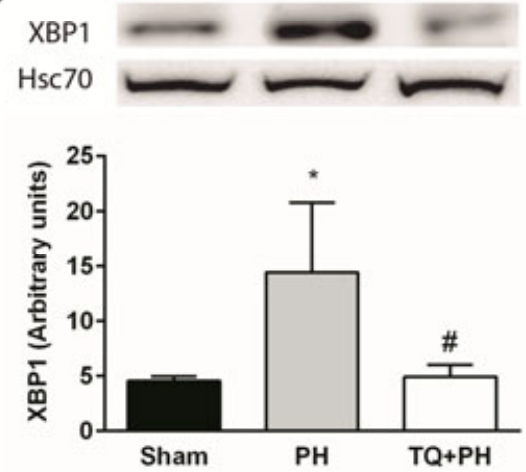

(b)

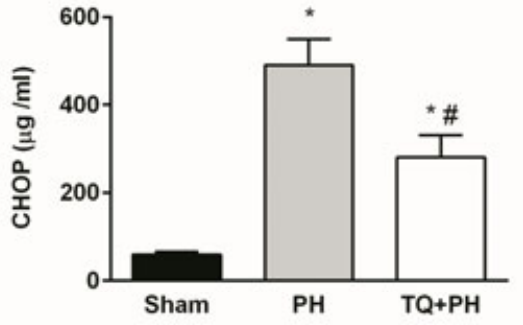

(d) ATF4 $\mathrm{Hsc70}$
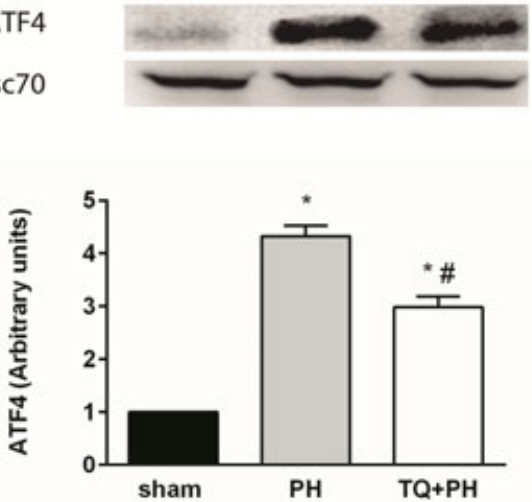

Figure 4 
(a)

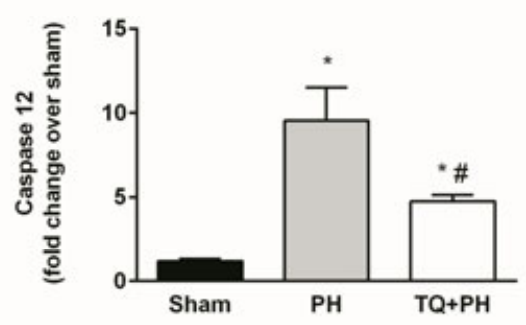

(c)

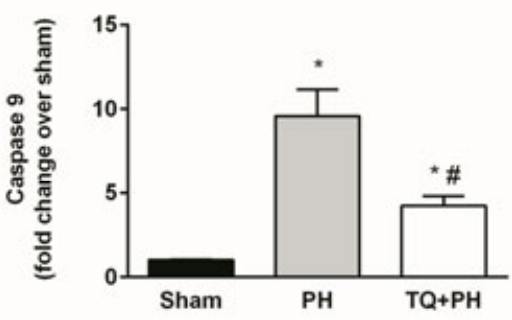

(b)

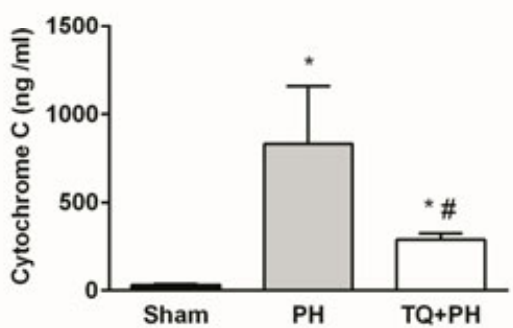

(d)

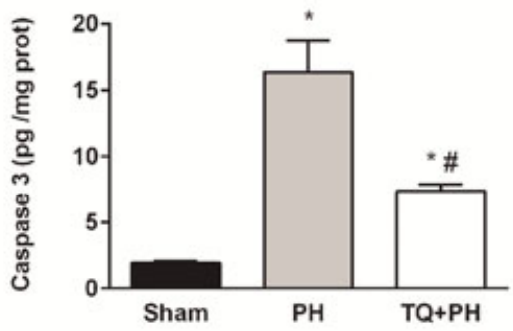

Figure 5 